\title{
A PRODUÇÃO DE FLORES NO ESTADO DO CEARÁ: ASPECTOS TECNOLÓGICOS, ECONÔMICOS E COMPETITIVOS
}

\author{
José Nilo de Oliveira Júnior ${ }^{1}$ \\ Ahmad Saeed Khan ${ }^{2}$ \\ Lúcia Maria Ramos Silva ${ }^{3}$
}

RESUMO - Este estudo procurou analisar a floricultura no Estado do Ceará, enfocando a produção de helicônias nos principais municípios produtores do Estado, mais precisamente avaliando o nível tecnológico empregado na produção e a rentabilidade da atividade e competitividade, em termos de eficiência dos produtores. A pesquisa realizou-se por meio de coleta de dados primários obtidos de entrevistas diretas com produtores nos municípios que compõem as regiões metropolitana e maciço de Baturité, de acordo com o cadastro da Secretaria de Agricultura Irrigada-SEAGRI, no período de outubro de 2002. Na avaliação do nível tecnológico dividiu-se o sistema de produção de helicônia em sete tecnologias: propagação, uso dos solos, adubação, tratos culturais, cuidados fitossanitários, gestão, colheita e pós-colheita. Daí, foram desenvolvidos índices tecnológicos para cada uma separadamente e para o conjunto delas, com base na respectiva tecnologia recomendada. $\mathrm{Na}$ avaliação da rentabilidade utilizou-se a metodologia do Sistema Integrado de Custos Agropecuários - CUSTAGRI e, na análise da competitividade, utilizaram-se os indicadores de eficiência como preços e custos e índice de lucratividade. Os principais resultados obtidos mostram que o nível tecnológico dos produtores de helicônia é considerado bom; a tecnologia de uso dos solos apresenta melhores índices; enquanto na tecnologia de cuidados fitossanitários foram encontrados os mais baixos índices. No que se refere à rentabilidade, a produção de helicônia é uma atividade rentável, visto que se constitui de baixos custos e pode chegar a altos índices de lucratividade.

Palavras-chave: floricultura, rentabilidade, tecnologia, Ceará.

\footnotetext{
${ }^{1}$ Doutorando em Economia na Universidade Federal do Ceará.

${ }^{2}$ Professor Titular do Departamento de Economia Agrícola da Universidade Federal do Ceará, Bolsista do CNPq. E-mail: saeed@ufc.br

${ }^{3}$ Professora Adjunta do Departamento de Economia Agrícola da Universidade Federal do Ceará. E-mail: lramos@ufc.br

Recebido em 25/09/2003 Aceito em 21/10/2003
} 


\section{Introdução}

\subsection{O problema e sua importância}

A floricultura é uma atividade que está inserida no segmento de agricultura irrigada, apresentando uma série de vantagens, como grande capacidade de geração de empregos diretos e indiretos. Segundo e Sawaya (2001), a floricultura é uma atividade de alta rentabilidade e intensiva em mão-de-obra, visto que emprega, em média, 15 pessoas por hectare, podendo trazer consequiências positivas como diminuição do êxodo rural, aumento da renda no campo, entre outras.

Apesar dos aspectos positivos mencionados, o Brasil, atualmente, encontra-se em um estágio de desenvolvimento muito abaixo de sua potencialidade. Segundo o Instituto Brasileiro de Floricultura - Ibraflor (2001), a área total de produção de flores e plantas ornamentais no país chegou a 4.850 ha, em 1999. Entre as regiões produtoras, o estado de São Paulo é responsável por cerca de $60 \%$ deste montante, principalmente os municípios de Holambra, Atibaia, Mogi das Cruzes, Piedade, Ibiúna, Guararema e Paranapanema, onde estão instalados os principais sistemas de distribuição atacadistas, os quais foram surgindo com o desenvolvimento do setor (Nogueira, 1996).

O estado do Ceará ainda possui pequena produção de flores, se comparado com outros como São Paulo, mas isto deve ser por pouco tempo, pois ele possui um conjunto de atrativos que podem estar contribuindo para a intensificação deste setor, como condições de microclimas favoráveis à produção de flores tropicais, complexo de distribuição privilegiado com portos modernos e bem equipados; terminal aéreo especializado em cargas, além de vôos diários para todo o país e para o mundo; malha rodoviária com cerca de 7 mil quilômetros; entre outras.

Com o intuito de consolidar o setor de floricultura, o governo estadual vem desenvolvendo amplo projeto de fomento a este segmento. Encontra-se em implantação cerca de 40 hectares, que representam, hoje, o 
maior investimento no cultivo de flores no país (Banco do Nordeste, 2001.). Além disto, vem investindo em qualificação, com introdução de programas de qualificação da mão-de-obra local, bem como na visão de clusters, com formação de agropolos que visam à atração de empresas, para consolidar, definitivamente, este segmento.

No Estado, merece destaque a produção de helicônias, que é a flor tropical mais cultivada no momento, além de crisântemos, antúrios e folhagens. Os principais municípios produtores de flores tropicais são os inseridos nos municípios do maciço de Baturité e região metropolitana de Fortaleza.

A helicônia é uma das flores tropicais mais atraentes, principalmente por ser uma flor exótica, de rara beleza. Segundo Berry e Kress (1991), existem mais de 450 nomes botânicos para as espécies, variedades e híbridos de helicônias. Há, ainda, mais de 200 cultivares e nomes comuns usados para fins comerciais e na literatura popular. Apesar de todos esses nomes (muitos dos quais aplicados às mesmas plantas), ainda há certa insegurança no número exato de espécies de helicônias, no entanto, estima-se que haja de 200 a 250 espécies.

Portanto, é importante a análise tecnoeconômica da floricultura no Estado do Ceará, destacando-se a produção de helicônias, uma vez que essa prática é uma novidade e, sem dúvida, pode vir a tornar-se muito competitiva, trazendo muitos benefícios para o Estado como um todo. A opção por analisar a produção de helicônias, e não outra, se deve ao fato de, no momento, esta ser uma das flores tropicais mais cultivadas no Estado e de não existir nenhum estudo em desenvolvimento.

\subsection{Objetivos}

\subsubsection{Objetivo geral}

O objetivo geral deste estudo é analisar a produção de helicônias no Estado do Ceará. 


\subsubsection{Objetivos específicos}

- Determinar e analisar o nível tecnológico dos produtores de helicônias;

- Determinar os indicadores de rentabilidade da atividade; e

- Analisar a competitividade entre os produtores.

\section{Referencial teórico}

\subsection{Aspectos conceituais de tecnologia}

Um dos problemas fundamentais da moderna economia dos países em desenvolvimento é a transformação da sua agricultura tradicional, pouco produtiva, em um setor moderno da economia. Segundo Santos (1977), a elevação da produtividade é uma questão de suma importância e pode ser resolvida pela geração de tecnologias.

Desse modo, é de grande relevância o papel da tecnologia no desenvolvimento das economias, como estratégia para superar e manter posições no mercado. São várias as teorias que tentam explicar sua natureza e sua importância para o desenvolvimento das economias. Evidentemente, cada definição procura atender aos objetivos específicos de seu autor, envolvendo diferentes contextos e graus de abrangência.

Na visão dos economistas clássicos, aqui representados por Adam Smith e David Ricardo, o processo de acumulação de capital seria interrompido pela impossibilidade de aumentar a produtividade do trabalho nas terras que seriam incorporadas na produção de alimentos.

Smith (1983), em A Riqueza das Nações, enfatizou que, além do número de trabalhadores envolvidos na produção, uma das principais fontes do crescimento das nações é o aumento da produtividade. Esse incremento seria resultado da divisão do trabalho, que proporcionaria maior destreza e habilidade aos trabalhadores, e da economia de tempo gerada pela utilização de máquinas. Já Ricardo (1982), no primeiro momento, não acreditava que o progresso tecnológico poderia trazer impactos sig- 
nificativos e sustentáveis na produtividade agrícola, porém, mais adiante, observou que uma das possibilidades para escapar da estagnação seria o progresso tecnológico, uma vez que este aumentaria a produtividade tanto da terra como do trabalho.

Schumpeter (1982), citado por Souza (2000), defendeu a noção de que a tecnologia é o elemento essencial na dinâmica capitalista. Desenvolveu uma teoria do desenvolvimento econômico baseado na idéia de inovação tecnológica bem abrangente, que estimularia grandes investimentos e a realização dos recursos em larga escala. Como resultado do processo de difusão e adoção dessa tecnologia, haveria expressivo crescimento econômico até o sistema ter-se adaptado a essa situação. Um novo surto de crescimento ocorreria apenas quando outra inovação tecnológica fosse introduzida na economia.

Na Teoria Neoclássica, os estudos relacionados com tecnologia não se aprofundaram até meados da década de 1950, quando os autores, em seus modelos de crescimento econômico, enfatizavam terra, capital e trabalho. Apesar de reconhecer o progresso tecnológico, este não era incluído formalmente no modelo. Hicks, citado por Silva (1995), introduziu a expressão inovação induzida ao estudar o assunto inovações técnicas. Observou que não havia razão para acreditar que as inovações fossem inerentemente poupadoras de trabalho, mas que os aumentos de salários induziam os empresários a procurar inovações que economizassem mão-de-obra para compensar aumentos nos seus custos.

De acordo com Rosenthal (1993), tecnologia é essencialmente conhecimento ou, mais especificamente, conhecimento útil, no sentido de ser aplicado (ou aplicável) às atividades humanas - especialmente, ainda que não exclusivamente, àquelas ligadas aos processos de produção, distribuição e utilização de bens e serviços - e de contribuir para elevação quantitativa e, ou, qualitativa dos resultados de tais atividades e processos. Entretanto, para Caldas (2000), à medida que se produzem novos produtos, processos e serviços, inovam-se os já existentes e criamse bases para promover a competitividade, condição necessária para o desenvolvimento econômico, ou seja, a inovação envolve muito mais do 
que simples mudanças em tecnologia; envolve conexões, interações e influências de muitos e variados graus - incluindo relacionamento entre empresas e empresas, entre empresas e centros de pesquisas, e entre empresas e Governo.

A contínua introdução de inovações tecnológicas e organizacionais, como parte do comportamento estratégico das empresas, constitui fator determinante na criação e manutenção da competitividade de uma indústria ou região econômica. Desse modo, a análise do que influencia as ações inovadoras estratégicas das empresas ajuda a explicar a dinâmica competitiva de uma região ou segmento produtivo.

\subsection{Aspectos conceituais de competitividade}

Em uma economia globalizada, muitas das vantagens competitivas são frutos dos fatores locais, razão por que ganham importância as concentrações geográficas de empresas (Porter, 1999). A concorrência atualmente é muito dinâmica. Os agentes econômicos podem ter vantagens de custo de insumo por meio de compras ao redor do mundo, o que torna a antiga noção de vantagem comparativa menos relevante. Hoje, a vantagem competitiva depende do uso mais produtivo dos insumos, o que requer constante inovação.

Segundo Ahearn et al. (1990), não há uma teoria geral da competitividade porque este não é termo estritamente econômico. No entanto, no conceito econômico de comércio, a vantagem comparativa é um elementochave da competitividade. Um país tem vantagem comparativa na produção de uma commodity agrícola particular se tiver o maior retorno por unidade de recurso fixo. As implicações comparativas são que cada país deveria produzir commodities para os quais tem oferta relativamente abundante de fatores fixos, como terra e trabalho. O custo médio de produção da indústria que dá origem à sua curva de oferta, em adição aos custos de entrega do produto no mercado, serviria então de base para medir a vantagem comparativa. 
Na teoria do comércio internacional, segundo Possas e Carvalho (1994), a idéia de competitividade internacional está intimamente interligada ao conceito de vantagens comparativas, sendo usados como termos equivalentes. A noção de competitividade internacional estaria, então, limitada à dos preços e custos, enquanto a teoria do comércio internacional às hipóteses de: a) Concorrência perfeita; b) Retornos marginais decrescentes; c) Preços determinados pela oferta e demanda; d) Igualdade das funções de produção para cada produto. Dessa forma, os custos e os preços poderiam ser tomados como indicadores da competitividade, já que seriam determinados pela dotação de fatores.

Competitividade é entendida como a habilidade de empresas, indústria, regiões ou áreas geográficas gerarem níveis relativamente altos de renda e emprego de fatores, em bases sustentáveis (Cepal, 1995). Para Haguenauer et al. (1996), competitividade é definida como a capacidade de uma empresa "formular e implementar estratégias concorrenciais que lhe permitam ampliar ou conservar, de forma duradoura, uma posição sustentável no mercado". A competitividade depende da adequação das estratégias das empresas aos padrões concorrenciais do mercado específico.

Perkins (1987), citado por Stülp (1993), considerou a competitividade como a habilidade de dominar uma parcela do mercado. Assim, uma empresa seria mais competitiva se conseguisse aumentar sua participação no mercado.

Farina e Zybersztajn (1994) definiram competitividade como resultado da conduta e do desempenho da empresa. A capacidade de sobrevivência e de expansão nos mercados nacionais e, ou, internacionais representa o desempenho. A segunda dimensão da competitividade, a conduta, está associada à noção de mercado, que, por sua vez, está associada ao processo de concorrência.

O progresso técnico é capaz de construir e destruir as vantagens competitivas, ou seja, para que uma firma seja competitiva, não é suficiente deter vantagens estáticas, mas ter capacidade de estar sempre à frente, 
recriando tais vantagens; para isso, deve ter conhecimento da tecnologia e investir em pesquisa e desenvolvimento, e em recursos humanos qualificados. Observa-se que a ênfase dada ao progresso técnico pode distorcer a análise, pois a importância deste como fontes de vantagens competitivas se dá de forma diferenciada, segundo os setores produtivos. Em determinados mercados, as firmas poderão ganhar espaço ao diferenciarem seu produto, ganhando nichos de mercado ou fortalecendo uma imagem favorável. Em outros mercados, tal espaço seria vão, o que levaria as firmas a buscarem outros tipos de vantagens competitivas, com expansão da escala, redução de custos, etc. (Possas e Carvalho, op. cit.).

As vantagens competitivas, ao contrário das comparativas associadas à adoção de fatores fixos, podem ser construídas por meio de medidas de política e investimentos específicos. Haguenauer et al. (op. cit.) também enfatizaram esse aspecto de criação e renovação das vantagens competitivas.

A competitividade de determinada empresa pode ser atribuída a vantagens comparativas ou competitivas. As imperfeições na economia real levam à conclusão de que a expressão vantagem competitiva é mais adequada para explicar a competitividade, já que considera as imperfeições de mercado como fatores determinantes da competitividade.

O uso de indicadores de competitividade que incorporem essa idéia de vantagens competitivas seria, portanto, mais adequado ao estudo do desempenho das empresas na economia.

\subsubsection{Indicadores de competitividade}

Os indicadores de eficiência relacionados com preços e, ou, custos de produção e com eficiência na utilização dos recursos são amplamente utilizados no Brasil e na literatura internacional, principalmente nos estudos de competitividade. Esses indicadores aparecem, às vezes, de forma complementar aos indicadores de desempenho, ou seja, como fatores determinantes do desempenho comercial, principalmente da performance das exportações. 
A evolução setorial da produtividade também tem merecido atenção de vários autores. Além de ser utilizada na complementação de outros indicadores, como no caso da evolução do custo da mão-de-obra, a produtividade setorial tem sido utilizada no monitoramento do grau de heterogeneidade da estrutura produtiva e da capacidade de resposta dos setores às diversas conjunturas econômicas dos últimos anos.

Segundo Kume (1988), no nível das empresas, os indicadores de eficiência mais utilizados são os de produtividade física ou monetária, tanto parcial quanto multifatorial, mas também aqueles relacionados com custos de produção e com lucratividade. Os principais indicadores de eficiência relacionados com preços e, ou, custos de produção e com eficiência na utilização dos recursos são os seguintes: a) Relação câmbio/salário; b) Taxa de câmbio real e real efetiva e variabilidade da taxa; c) Custo unitário relativo da mão-de-obra e custo absoluto de mão-de-obra; d) Participação dos salários no valor da produção; e) Relação preço de exportação do País e dos demais países concorrentes; f) Relação preço doméstico e preço de exportação e, ou, de importação; g) Produtividade da mão-de-obra; h) Produtividade multifatorial; i) Indicadores de qualidade dos produtos (participação dos produtos defeituosos no total, número de reclamações, número de devoluções, ocorrências no tempo certo etc.).

Os diversos conceitos de competitividade existentes na literatura dão origem aos indicadores de competitividade, que são classificados das mais diversas formas, destacando-se alguns enfoques: a) Microeconômico - que associa competitividade à aptidão de uma empresa na produção e venda de determinado produto; e macroeconômico - que associa competitividade à capacidade de as economias nacionais apresentarem resultados econômicos satisfatórios relacionados com comércio internacional e, ou, com nível de vida e bem-estar social (Chudnovosky, 1990, apud Pagano, 2001); b) Desempenho - que preconiza a existência de maior competitividade se um país aumentar sua participação no mercado internacional (uma versão mais avançada seria o modelo constant market-share), e eficiência - que enfatiza a performance do país no 
mercado internacional (Haguenauer, 1990, apud Pagano, op. cit.); c) Alguns indicadores são utilizados na distinção entre competitividade autêntica - que se refletiria no bom desempenho das exportações, em conseqüência da eficiência e competitividade espúria - que se refere à utilização de variáveis macroeconômicas (Fajnzylber, 1988, apud Pagano, op. cit.) e d) Há um enfoque que ressalta a produtividade das empresas internas como principal elemento gerador de competitividade, independente da competição internacional (Krugman, 1994, apud Pagano, op. cit.).

Para Araújo e Campos (1994), existem duas formas de abordagem para se fazer uma análise de competitividade: a primeira é a ex-post, que avalia a atual posição de competitividade de determinado setor produtivo de um país a partir de sua posição nos mercados interno e externo; a segunda é a ex-ante, que se refere à capacidade competitiva, no longo prazo.

Existem também indicadores de custo de mão-de-obra que podem ser utilizados em diferentes interpretações, conforme a acepção do conceito de competitividade. Segundo Hagnauer (1989), um indicador de custo de mão-de-obra é a elevação mais que proporcional dos salários (mais encargos sociais) em relação à produtividade, ao câmbio, aos preços industriais no atacado ou em relação ao custo de mão-de-obra dos países concorrentes no mercado internacional, que, nesse caso, representaria perda de competitividade. A questão de quem deve financiar os encargos sociais, se os próprios trabalhadores, se os empresários, ou se a sociedade como um todo, tem relação direta com a competitividade.

Andrade e Reis (1994), Villwock e Gioacomini (1994) e Neves et al. (1992) utilizaram em seus estudos, para fazer comparações entre empresas, alguns indicadores de competitividade, destacando-se custo de produção, preço e lucratividade. 


\section{Metodologia}

\section{1. Área de estudo e origem dos dados}

A pesquisa foi realizada na região do maciço de Baturité e na metropolitana de Fortaleza, as quais estão inseridas nos principais pólos produtores de flores tropicais do Estado do Ceará, identificados com base nos cadastros da Secretaria de Agricultura Irrigada - SEAGRI. Como mencionado anteriormente, foi analisada a produção de helicônias.

Os municípios que compõem a região metropolitana de Fortaleza, de acordo com o cadastro da SEAGRI, são Maranguape, Eusébio, Aquiraz, Paracuru e Paraipaba. Já a região do Maciço de Baturité inclui os municípios de Baturité, Guaramiranga e Pacoti. Estes municípios foram escolhidos porque, até a data de realização das entrevistas, continham a totalidade dos produtores de helicônias no Estado.

Os dados utilizados na pesquisa são de origem primária, obtidos de entrevistas diretas aos produtores de helicônias inseridos nesses municípios, no mês de outubro de 2002 . No total de 10 produtores de helicônias identificados no Estado, foram entrevistados nove produtores contidos nos municípios em estudo.

\subsection{Métodos de análise}

\subsubsection{Nível tecnológico}

Para proceder à identificação do nível tecnológico, foram consideradas as seguintes tecnologias, com base em Lamas (2001): propagação; uso dos solos; adubação; tratos culturais; cuidados fitossanitários; gestão; colheita; e pós-colheita. 


\subsubsection{Determinação do nível tecnológico}

A construção de índices tecnológicos, para se proceder à avaliação dos padrões tecnológicos dos produtores, parte da consideração e do tratamento das variáveis especificadas. Os dados obtidos na pesquisa de campo compreendem informações sobre a utilização das práticas de cada tecnologia.

Para determinação do nível tecnológico será, inicialmente, obtido o índice relativo à tecnologia $n$ para o produtor $j\left(\operatorname{In}_{j}\right)$, com base em Miranda (2001), como a seguir:

$\operatorname{In}=\sum_{i=y}^{m} \frac{a_{i}}{w_{n}}$

sendo $w_{n}=\operatorname{Max} \sum_{i=y}^{m} a_{i}$; dessa forma, $0 \leq \operatorname{In}_{j} \leq 1$.

em que:

$I n_{\mathrm{j}}=$ índice da tecnologia $n$ do produtor $j$;

$i=$ técnicas empregadas;

$n=$ tecnologia utilizada;

$[y, m]=$ variáveis dentro do segmento $i$, referentes à tecnologia $n$; $a_{i}=$ valor da adoção da variável $x_{i}$ da tecnologia $n$.

Assim, $\frac{a_{i}}{w_{n}}$ representa o peso de cada variável $\mathrm{x}_{i}$ na constituição do índice tecnológico específico $n$, e para a tecnologia de propagação, para a tecnologia de solos, $\mathrm{n}=1, i=[1] \mathrm{e} \quad \mathrm{w}_{1}=3$ para a tecnologia de adubação, $\mathrm{n}=2, i=[2 ; 7] \mathrm{e} \quad \mathrm{w}_{2}=8$ para a tecnologia de tratos culturais, $\mathrm{n}=3, i=[8 ; 13]$ e $\quad \mathrm{w}_{3}=6$ para a tecnologia de fitossanidade, $\mathrm{n}=4, i=[14 ; 21]$ e $_{4}=8$ para a tecnologia da gestão, $\mathrm{n}=5, i=[22 ; 27]$ e $_{5}=6$ para a tecnologia de pós-colheita, $\mathrm{n}=6, i=[28 ; 34]$ e $_{6}=7$ $\mathrm{n}=7, i=[35 ; 46]$ e $_{7}=11$ 
O índice tecnológico médio específico para o conjunto de produtores é dado pelo somatório dos índices específicos dos produtores individuais dividido pelo número de produtores entrevistados, demonstrado pela equação

$I T n=\frac{1}{z} \sum_{j=1}^{z} I n j$,

em que:

$\mathrm{j}$ = número de produtores (que varia de $1 \mathrm{a} \mathrm{z}$ );

$n=$ tecnologia utilizada.

Neste estudo, o índice tecnológico do produtor será determinado pelas tecnologias em análise, que se constituem de propagação, uso dos solos, adubação, tratos culturais e cuidados fitossanitários, colheita e pós-colheita e gestão. Nesse caso, utiliza-se a média do somatório dos índices específicos das referidas tecnologias, explicitados pela equação:

$I P_{j}=\frac{1}{7} \sum_{1}^{7} I n j$.

Assim, o índice tecnológico da produção de helicônias na área de estudo será assim expresso:

$I G=\frac{1}{J} \sum_{1}^{j} I P_{j}$.

Com base nos valores obtidos dos índices (que variam de zero a um), determina-se o nível tecnológico dos produtores de helicônias, considerando-se que, quanto mais próximo do valor máximo (um), melhor será o nível tecnológico dos respectivos produtores. 
3.2.2. Análise da rentabilidade financeira e da competitividade da floricultura

Para atender ao segundo e terceiro objetivos, foram determinados os custos e receitas da produção de flores. A determinação dos custos e dos indicadores de rentabilidade que foram empregados nesta pesquisa tem por base os conceitos utilizados por Martin et al. (1998) no desenvolvimento do Sistema Integrado de Custos Agropecuários (CUSTAGRI), pesquisa feita com a cooperação entre o Instituto de Economia Aplicada (IEA) em parceria com o Centro Nacional de Pesquisa Tecnológica em Informática para a Agricultura (CNPTIA - EMBRAPA).

\section{Resultados e discussão}

\subsection{Nível tecnológico}

Para proceder à comparação entre os níveis de tecnologia adotada pelos produtores de helicônias, definiram-se padrões tecnológicos, em que se estabeleceram intervalos dos valores dos índices tecnológicos associados a cada padrão definido. Os padrões que correspondem aos maiores valores dos índices são considerados melhores; assim, classificaram-se os produtores de helicônias nos seguintes padrões:

Padrão A: quando o índice ficar entre 0,75 e 1,00, ou seja, 0,75 $\leq I 1,00$

Padrão B: quando o índice ficar entre 0,50 e 0,75, ou seja, 0,50 $I<0,75$ Padrão C: quando o índice ficar entre 0,25 e 0,50, ou seja, 0,25 $I<0,50$ Padrão D: quando o índice ficar entre 0 e 0,25, ou seja, $0 I<0,25$ Sendo $I$ o valor obtido em cada índice considerado na pesquisa. 
4.2.1. Índice tecnológico geral dos produtores de helicônias no estado do Ceará

No desenvolvimento de cada índice para avaliação do nível tecnológico, consideraram-se a contribuição que cada tecnologia teve na composição e a sua respectiva participação percentual. Há de se levar em conta o fato de que:

- IG : compreende as tecnologias de propagação, utilização dos solos, adúbação, tratos culturais e cuidados fitossanitários;

- $I G$ : compreende as cinco tecnologias anteriores mais a colheita e pós-colheita; e

- IG : índice médio geral que avalia o nível tecnológico geral da produção de helicônia, englobando todas as tecnologias.

4.2.1.1. Índice referente a propagação, uso dos solos, adubação, tratos culturais e cuidados fitossanitários e a contribuição de cada tecnologia para o índice médio geral $\left(\mathrm{IG}_{1}\right)$

Conforme Tabela 1, pode-se observar que o índice geral apresentou valor de $I G_{1}=0,516$, o que indica que os produtores, em conjunto, se encontravam no padrão $\mathrm{B}$, sendo o menor índice de $I P_{1}=0,41$ e o maior de $I P_{1}=0,70$. Dos produtores entrevistados, 55,55\% encontravam-se no padrão C e $44,45 \%$, no padrão $B$. 
Tabela 1 - Contribuição de cada tecnologia na composição do índice médio geral referente a propagação, uso dos solos, adubação, tratos culturais e cuidados fitossanitários $\left(I G_{I}\right)$

\begin{tabular}{lc|c}
\hline \multicolumn{1}{c}{ Especificação } & \multicolumn{2}{c}{ Valor } \\
\cline { 2 - 3 } & Absoluto & Relativo \\
\hline Propagação & 0,081481 & 15,77 \\
Utilização dos solos & 0,163889 & 31,73 \\
Adubação & 0,125926 & 24,37 \\
Tratos culturais & 0,108333 & 20,96 \\
Cuidados fitossanitários & 0,037037 & 7,17 \\
$\boldsymbol{I G}_{\boldsymbol{I}}$ & $\mathbf{0 , 5 1 6 6 6 7}$ & $\mathbf{1 0 0 , 0 0}$ \\
Menor indicador & 0,41 & - \\
Maior indicador & 0,70 & - \\
\hline
\end{tabular}

Fonte: Dados da pesquisa.

A maior participação na composição do índice geral foi do indicador referente a uso dos solos, com $31,73 \%$, enquanto a menor participação ficou com o indicador referente a cuidados fitossanitários.

Dessa forma, de acordo com os valores obtidos para $I G_{1}$, pode-se considerar bom o nível tecnológico dos produtores de helicônias, haja vista que mais de 50\% das técnicas recomendadas são utilizados.

4.2.1.2. Índice referente a propagação, uso dos solos, adubação, tratos culturais, cuidados fitossanitários, colheita e póscolheita e a contribuição de cada tecnologia no índice médio geral $\left(\mathrm{IG}_{2}\right)$

Com a introdução da tecnologia de colheita e pós-colheita, os resultados de algumas tecnologias pioraram, como foi o caso da tecnologia de uso dos solos, que caiu, em termos absolutos, de 0,16389 para 0,136574. O mesmo ocorreu com as tecnologias de propagação, adubação, tratos culturais (Tabela 2).

Com relação ao índice geral, observou-se pequena melhora, uma vez que o valor encontrado foi de $I G_{2}=0,543$, compatível com o padrão B, 
no qual se encontravam $44,45 \%$ dos produtores, ficando os $55,55 \%$ restantes situados no padrão tecnológico $\mathrm{C}$.

Pode-se observar, ainda, que a tecnologia referente à utilização dos solos obteve a maior participação na formação do índice geral, com 25,15\%, enquanto a referente aos cuidados fitossanitários obteve a menor participação, apenas 5,68\%. A tecnologia referente à propagação obteve $12,50 \%$ de participação, enquanto as de adubação e de tratos culturais obtiveram, respectivamente, $19,31 \%$ e $16,61 \%$ de participação.

Tabela 2 - Contribuição de cada tecnologia na composição do índice geral referente a propagação, uso dos solos, adubação, tratos culturais, cuidados fitossanitários, colheita e pós-colheita $\left(I G_{2}\right)$

\begin{tabular}{lcc}
\hline \multirow{2}{*}{ Especificação } & \multicolumn{2}{c}{ Valor } \\
\cline { 2 - 3 } & & Relativo \\
\hline Propagação & 0,067901 & 12,50 \\
Utilização dos solos & 0,136574 & 25,15 \\
Adubação & 0,104938 & 19,31 \\
Tratos culturais & 0,090278 & 16,61 \\
Cuidados fitossanitários & 0,030864 & 5,68 \\
Colheita e pós-colheita & 0,112654 & 20,75 \\
$\boldsymbol{I G}_{2}$ & $\mathbf{0 , 5 4 3 2 1}$ & $\mathbf{1 0 0 , 0 0}$ \\
Menor indicador & 0,36 & - \\
Maior indicador & 0,73 & - \\
\hline
\end{tabular}

Fonte: Dados da pesquisa.

Assim, conforme os valores obtidos para o $I G_{2}$, considera-se o nível tecnológico bom, haja vista que cerca de $54 \%$ das tecnologias recomendadas estavam sendo utilizados. 
4.2.1.3. Índice médio geral de todas as tecnologias e suas respectivas contribuições $\left(\mathrm{IG}_{3}\right)$

Com a introdução da tecnologia da gestão, os valores dos índices reduziram-se. $O$ índice geral encontrado foi de $I G_{3}=0,526$, mas continua dentro do padrão tecnológico B, este fato que pode ser explicado pelos baixos índices que a tecnologia da gestão apresentou nos municípios pesquisados.

Verificou-se que 55,55\% dos produtores encontravam-se no padrão C, o restante, no padrão tecnológico B. Portanto, o índice tecnológico geral pode ser considerado bom, visto que os produtores adotaram mais de $52 \%$ da tecnologia recomendada (Tabela 3 ).

Dossa et al. (1994), em seus estudos sobre erva-mate no município de Machadinho, Rio Grande do Sul, encontraram resultados semelhantes para o nível tecnológico, porém ressaltaram que, apesar de o resultado ter sido considerado bom, este ainda não é o nível tecnológico ideal para se ter competitividade no mercado internacional. 
Tabela 3 - Contribuição de cada tecnologia na composição do índice médio geral referente a propagação, uso dos solos, adubação, tratos culturais, cuidados fitossanitários, colheita e póscolheita e a gestão $\left(I G_{3}\right)$

\begin{tabular}{l|cc}
\hline \multirow{2}{*}{ Especificação } & \multicolumn{2}{c}{ Valor } \\
\cline { 2 - 3 } & Absoluto & Relativo \\
\hline Propagação & 0,058201 & 11,05 \\
Utilização dos solos & 0,117063 & 22,22 \\
Adubação & 0,089947 & 17,08 \\
Tratos culturais & 0,077381 & 14,69 \\
Cuidados fitossanitários & 0,026455 & 5,02 \\
Gestão & 0,061224 & 11,62 \\
Colheita e pós-colheita & 0,096561 & 18,32 \\
IG & $\mathbf{0 , 5 2 6 8 3 3}$ & $\mathbf{1 0 0 , 0 0}$ \\
Menor indicador & 0,38 & - \\
Maior indicador & 0,74 & - \\
\hline
\end{tabular}

Fonte: Dados da pesquisa.

Observa-se, ainda, que a tecnologia referente à utilização dos solos obteve a maior participação na formação do índice médio geral, 22,22\%, enquanto a referente aos cuidados fitossanitários alcançou a menor participação, apenas 5,02\%.

\subsubsection{Variabilidade das Tecnologias}

Considerando-se os índices de todas as tecnologias que formam o nível tecnológico de produção de helicônias, observou-se que houve grande variação entre os valores mínimos e máximos encontrados, ou seja, entre os entrevistados, houve certa variação nos padrões tecnológicos para uma mesma tecnologia, e entre tecnologias (Tabela 4).

O comportamento dos produtores foi diferente para cada tecnologia, a exemplo da tecnologia de uso dos solos, em que os produtores se encontravam, em média, no padrão A, enquanto para a tecnologia de cuidados fitossanitários, no padrão D. 
Da análise dos valores dos desvios-padrão dos indicadores tecnológicos, observa-se que existe heterogeneidade entre os níveis tecnológicos adotados pelos produtores, tendo o maior desvio-padrão sido encontrado na tecnologia de propagação $(0,277)$ e o menor, no uso dos solos $(0,154)$.

Tabela 4 - Variações dos níveis tecnológicos, de acordo com as tecnologias e índices calculados

\begin{tabular}{l|c|c|c|c}
\hline Especificação & Mínimo & Máximo & Média & Desvio-Padrão \\
& & & & \\
\hline Propagação & 0 & 0,666 & 0,407 & 0,277 \\
Utilização dos solos & 0,50 & 1 & 0,819 & 0,154 \\
Adubação & 0,50 & 1 & 0,629 & 0,246 \\
Tratos culturais & 0,375 & 0,875 & 0,541 & 0,176 \\
Cuidados fitossanitários & 0 & 0,666 & 0,185 & 0,242 \\
Gestão & 0,142 & 0,857 & 0,428 & 0,247 \\
Colheita e pós-colheita & 0,416 & 0,916 & 0,675 & 0,178 \\
\hline
\end{tabular}

Fonte: Dados da pesquisa.

\subsection{Determinação das receitas e dos custos}

Os valores monetários referentes à análise de rentabilidade econômica da produção de helicônias estão expressos em reais $(\mathrm{R} \$)$, de outubro de 2002. A receita bruta foi computada pela produção de cada produtor, multiplicada pelo preço médio de venda ${ }^{4}$, no período considerado. Dessa forma, obteve-se um valor médio da receita bruta, por 1000 hastes, de $\mathrm{R} \$ 1155,55$ (Tabela 5).

Na determinação do custo operacional efetivo (COE) foram consideradas as despesas com mão-de-obra e com demais insumos. No que se refere aos insumos, foram computadas as despesas com fertilizantes, calcário dolomítico, adubos orgânicos, inseticidas, energia elétrica, combustível, caixas de papelão e defensivos. Dessa forma, o custo operacional efetivo alcançou um valor de $\mathrm{R} \$ 578,62$, que corresponde a 50,07\% da

${ }^{4} \mathrm{O}$ preço médio de uma unidade de helicônia (haste) foi de $\mathrm{R} \$ 1,15$. 
receita bruta obtida (Tabela 5). Pode-se observar que, se forem consideradas somente as despesas efetivamente desembolsadas pelo produtor, houve sobra de recursos da ordem de $49,92 \%$ ou de $\mathrm{R} \$ 576,93$.

Tabela 5 - Receita e custo de produção de 1000 hastes de helicônias

$$
\text { Valor total }
$$

Item

$(\mathrm{R} \$ / 1000$ hastes $)$

\begin{tabular}{lc}
\hline Receita bruta (RB) & 1155,55 \\
Custo operacional efetivo (COE) & 578,62 \\
Mão-de-obra & 262,79 \\
Insumos & 315,82 \\
Custo operacional total (COT) & 740,95 \\
COE & 578,62 \\
Depreciação & 69,91 \\
Manutenção & 29,35 \\
Seguro & 16,77 \\
Encargos financeiros & 17,35 \\
Outras despesas operacionais & 28,92 \\
Custo total de produção & 898,48 \\
COT & 740,95 \\
Remuneração do capital & 87,16 \\
Remuneração da terra & 70,41 \\
\hline
\end{tabular}

Fonte: Dados da pesquisa.

No cálculo do custo operacional total (COT), adiciona-se ao valor obtido do $\mathrm{COE}$ às despesas com depreciação, manutenção, seguro, encargos financeiros e a outras despesas operacionais. O valor encontrado foi de $\mathrm{R} \$ 740,95$, que correspondeu a $64,12 \%$ da receita bruta gerada na produção de 1000 hastes de helicônia. O montante que sobrou para o produtor, após pagar todas as despesas operacionais, correspondeu a 38,87\% da receita bruta ou o equivalente a $\mathrm{R} \$ 414,60$. Portanto, no curto prazo, os produtores de helicônia cobriram todos os custos operacionais de produção, bem como o custo referente à reposição de maquinaria, um fator importante para a produção. 
Por sua vez, o custo total de produção (CTP) foi obtido pela adição do $\mathrm{COT}$ às remunerações do capital e da terra. $\mathrm{O}$ valor encontrado foi de $\mathrm{R} \$ 898,48$, que correspondeu a $77,75 \%$ da receita bruta obtida na produção de 1000 hastes de helicônia. Isso implica que a produção cobriu todos os seus custos, sobrando um montante de $\mathrm{R} \$ 257,07$, que equivaleu a $22,24 \%$ da receita bruta.

\subsection{Determinação dos indicadores de rentabilidade}

De acordo com a Tabela 6, pode-se observar que a margem bruta do custo operacional efetivo (MBCOE) apresentou um valor de 99,70\%, que significa que os produtores dispunham de quantidade de recursos 99,70\% superior ao custo operacional efetivo (COE), que poderão ser utilizados para cobrir os demais custos operacionais. A margem bruta relativa ao custo operacional total (MBCOT) foi de 55,95\%, significando que, após pagar todos os custos operacionais, sobraram recursos neste montante que servirão para remunerar o capital, a terra e a capacidade empresarial do proprietário.

Tabela 6 - Indicadores de rentabilidade para a produção de 1.000 hastes de helicônias

\begin{tabular}{lc}
\hline Item & Valor otal \\
\hline Receita bruta $(\mathrm{R} \$)$ & 1100,00 \\
Custo total $(\mathrm{R} \$)$ & 898,48 \\
MBCOE $(\%)$ & 99,70 \\
MBCOT $(\%)$ & 55,95 \\
MBCTP (\%) & 28,61 \\
PNCOE (hastes) & 503,14 \\
PNCOT (hastes) & 644,30 \\
PNCTP (hastes) & 781,29 \\
Lucro operacional $(\mathrm{R} \$)$ & 414,60 \\
Indice de lucratividade $(\%)$ & 35,87 \\
\hline
\end{tabular}

Fonte: Dados da pesquisa. 
A margem bruta do custo total de produção (MBCTP) apresentou valor de $28,61 \%$, o que mostra que a receita gerada, nas condições descritas no estudo, foi suficiente para pagar todos os custos de produção de 1.000 hastes de helicônias, sobrando o valor de $22,42 \%$ para remunerar a capacidade empresarial do produtor.

Os valores obtidos dos pontos de nivelamento, associados a COE, COT e CTP, foram de 503,14 hastes, 644,30 hastes e 781,29 hastes, respectivamente. Portanto, esses resultados são consistentes com os apresentados anteriormente, ou seja, com essa produtividade e com o preço vigente considerado, o produtor conseguiu arcar com todos os custos de produção, obtendo um resíduo que poderá remunerá-lo.

O lucro operacional (LO), que é dado pela diferença entre a receita bruta e o custo operacional total, apresentou um valor de $\mathrm{R} \$ 414,60$, que indica que os produtores apresentam, no curto prazo, boas condições econômicas e operacionais, confirmando, mais uma vez, os resultados encontrados.

Por sua vez, o índice de lucratividade (IL) apresentou um valor de 35,87\%, que indica que os produtores dispunham de $35,87 \%$ da receita da atividade após o pagamento de todos os custos operacionais.

Portanto, a produção de helicônia, no contexto da agricultura irrigada, mostrou resultados que devem ser exaltados e que a floricultura possui um grande potencial a ser explorado no Estado.

\subsection{Análise da competitividade}

De acordo com Tabela 7, podem-se observar o custo unitário de produção, o preço de venda praticado por produtor e o índice de lucratividade. 
Tabela 7 - Indicadores de competitividade relacionados com os produtores de helicônia no Ceará

\begin{tabular}{c|c|c|c}
\hline Produtores & $\begin{array}{c}\text { Custo unitário de } \\
\text { produção }(\mathrm{R} \$)\end{array}$ & $\begin{array}{c}\text { Preço de venda } \\
\text { (R \$/haste) }\end{array}$ & $\begin{array}{c}\text { Índice de } \\
\text { lucratividade }(\%)\end{array}$ \\
\hline 1 & 0,290 & 1,00 & 72,90 \\
2 & 0,607 & 1,50 & 69,94 \\
3 & 0,840 & 1,00 & 35,49 \\
4 & 0,869 & 1,00 & 23,40 \\
5 & 0,897 & 1,00 & 27,83 \\
6 & 0,961 & 1,00 & 15,59 \\
7 & 1,084 & 1,20 & 30,11 \\
8 & 1,159 & 1,20 & 11,56 \\
9 & 1,374 & 1,50 & 28,65 \\
\hline
\end{tabular}

Fonte: Dados da pesquisa.

Assim, conforme dados da Tabela 7, observa-se que o produtor 1 foi o mais competitivo entre os produtores de helicônias nos municípios pesquisados, pois apresentou o menor custo unitário de produção, no valor de $R$ \$ 0,290 , e um preço de venda de $R \$ 1,00$, tendo um lucro unitário de $\mathrm{R} \$ 0,71$ em cada haste de helicônia vendida, o que equivale à rentabilidade, expressa pelo índice de lucratividade, de 72,90\%.

Já o produtor 9 foi o que apresentou o maior custo unitário de produção, entre todos, visto que o valor do custo de produção foi de $\mathrm{R} \$ 1,374$ e o preço de venda, de $\mathrm{R} \$ 1,50$, o que representa um lucro unitário de $\mathrm{R} \$$ 0,126 por haste vendida, equivalente a uma rentabilidade de $28,65 \%$.

A explicação para isso pode derivar do fato de que, como existem diferentes microclimas no Estado e estes apresentam características distintas, certas práticas recomendadas, no âmbito geral, podem ser, ou não, necessárias a um produtor em particular, o que contribui sobremaneira para o resultado tanto do nível tecnológico como dos custos de produção.

Um fato importante constatado foi com relação ao destino dado às produções, isto é, alguns produtores venderam sua produção direto ao mer- 
cado local e outros, a intermediários. A explicação para esse fato, segundo os próprios produtores, é a questão de acesso ao mercado, ou seja, são dependentes de intermediários, o que pode trazer várias conseqüências ao setor, como, por exemplo, distorções nos preços e nos ganhos de cada produtor, que, no médio e longo prazo, podem vir a se tornar um desestímulo ao desenvolvimento do setor ${ }^{5}$.

\section{Conclusões}

Os resultados encontrados neste estudo permitem obter diversas conclusões a respeito da produção de helicônias nos municípios cearenses pesquisados.

Os resultados permitem concluir que a adoção de práticas agrícolas recomendadas para a atividade contribuem sobremaneira para melhor desempenho do setor. Assim, o nível tecnológico dos produtores foi considerado bom, uma vez que estes ficaram inseridos no padrão $\mathrm{B}$, o que implica que mais de $50 \%$ da tecnologia recomendada foi usada pelos produtores.

A tecnologia de uso dos solos foi a que apresentou melhor nível tecnológico, o que se explica pelo fato de serem utilizados solos ricos em matérias orgânicas, solos profundos e solos porosos dos produtores.

No entanto, observou-se dispersão do índice tecnológico entre os produtores, o que implica certa heterogeneidade nas práticas culturais. Com isso, nota-se ausência, na produção de helicônias, de um "pacote" tecnológico específico que atenda às características dos microclimas cearenses.

A produção de helicônias é uma atividade rentável, visto que pode chegar a elevados índices de lucratividade. Os produtores com maiores con-

\footnotetext{
${ }^{5}$ É importante salientar que pequena parte da produção, de acordo com informações dos órgãos competentes, é exportada esporadicamente.
} 
dições de competitividade são aqueles com menores custos, o que gera maiores índices de lucratividade. Verificou-se, também, que a competitividade foi influenciada positivamente pelo nível tecnológico.

Dificuldades encontradas na utilização de tecnologias recomendadas podem estar relacionadas com a falta de assistência técnica dada ao produtor. Desse modo, sugere-se que este serviço seja intensificado, uma vez que é de suma importância para o desenvolvimento do setor.

É importante também que os órgãos competentes ofereçam maiores condições para o escoamento da produção, mediante a criação de um mercado atacadista de flores, que siga modelos já implementados em outros estados.

\section{Referências bibliográficas}

AHEARN, M., CULVER, D., SCHONEY, R. Usefulness and limitations of COP estimates for evaluating international competitiveness: a comparison of Canada and U.S. wheat. American Journal of Agricultures Economics, Virginian, v.72, n.5. no.5, 1990. p. 1283 1291.

ANDRADE, J. P. e REIS, R. P. A. Competitividade do complexo lácteo no mercosul: estudos de multicaso em Minas Gerais. In: Congresso Brasileiro de Economia e Sociologia Rural, 32. Brasília, 1994, Anais ... Brasília, SOBER, 1994. p.603-621.

ARAÚJO, C. M. M., CAMPOS, A. C. Competitividade de diferentes sistemas de produção de leite em Minas Gerais frente ao mercosul. In: Congresso Brasileiro de Economia e Sociologia Rural, 32, Brasília, Anais...Brasília: SOBER, 1994, p. 564-581.

BANCO DO NORDESTE. A importância do agronegócio da irrigação para o desenvolvimento do Nordeste. Vol. 1, Série: Políticas e Estratégias para um Novo Modelo de Irrigação. 2001. 
BERRY, F. e KRESS, W. J. Heliconia: an identification guide. Smithsonian Instituition Press, Washington and London. 1991. 334p.

CALDAS, R. A. A construção de um modelo de arcabouço legal para ciência, tecnologia e inovação. Visões Estratégicas. 2000.

CEPAL. Indicadores de competitividad y productividad, revisión analítica y propuesta sobre su utilización. Santiago de Chile, CEPAL/ PNUD, (Serié Desarrollo Productivo, 27). 1995.

FARINA, E. M. M. Q.; e ZYLBERSZTAJN, D. Competitividade e organização das cadeias agroindustriais. Costa Rica: Instituto Interamericano de Cooperação para a Agricultura, 1994. 63p.

IBRAFLOR. Brasil: mostra tua flora. Informativo, v. 7, n. 23, mar, 2001. 4p.

HAGUENAUER, L. Competitividade: conceitos e medidas. uma resenha da bibliografia recente com ênfase no caso brasileiro. Rio de Janeiro, IEI/UFRJ, Texto para Discussão n²11, 1989. 24p.

HAGUENAUER, L., FERRAZ, J. C., KUPFER, D.S. Competição e internacionalização na indústria brasileira. In: O Brasil e a Economia Global. Renato Baumann (org). Rio de Janeiro, Campus. 1966. $158 \mathrm{p}$.

KUME, H. Defasagem justifica mudança? Revista Brasileira de Comércio Exterior, $n^{\circ} 18,1988$. 18p.

LAMAS, A. M. Floricultura tropical: técnicas de cultivo. Recife. SEBRAE/PE, Série Empreendedor 5. 2001.

MARTIN, N. B., SERRA, R., OLIVEIRA, M. D. M., et al. Sistema integrado de custos agropecuários - CUSTAGRI. Informações Econômicas, São Paulo, v. 28, nº1, jan. 1998. p. 7-28. 
MIRANDA, E. A. A.Inovações tecnológicas na viticultura do submédio São Francisco. Recife: PIMES/UFPE, 2001. 191f. (Tese de Doutorado).

NEVES, E. M., ANDIA, L. H., NEVES M. F e BARROS, S. S. Economia da produção cítricola: competitividade sob o enfoque de custos e investimentos . In: Congresso Brasileiro de Economia e Sociologia Rural, 30. Brasília, 1992, Anais ... Brasília, SOBER, 1992. p.525-537.

NOGUEIRA, A. J. F. Mercado de flores de corte e plantas ornamentais. Bahia Agrícola. Vol. 1, nº 2, out. 1996. 8p.

PAGANO, L. Conceito de competitividade. Revista da ESCM - Jul/ Ago. 2001. São Paulo, 2001.v.08, ano 07, edição 04.

PORTER, M. E. Clusters e competitividade. Revista HSM Manegement - jul/ago. 1999. 11p.

POSSAS, M. S., CARVALHO, E. G. Competitividade internacional: um enfoque teórico. In: Congresso Brasileiro de Economia e Sociologia Rural, 32, Brasília, Anais...Brasília: SOBER, 1994: p 1211-1229.

RICARDO, David. Princípios de economia política e tributação. São Paulo, Abril Cultural, (Série os Economistas), 1982.347p.

ROSENTHAL, D. Capacitação tecnológica - uma sugestão de arcabouço conceitual de referência. In: Seminário de Desenvolvimento Econômico do Departamento de Economia da Universidade da Califórnia, Berkeley ... Anais, Berkeley, 1993. 39p.

SANTOS, M. M. Fatores socioculturais e econômicos relacionados com adotabilidade de práticas agropecuárias no Estado de Minas Gerais. Viçosa: UFV, 1977. 142f. (Dissertação de Mestrado). 
SILVA, C. R. L. Inovação tecnológica e distribuição de renda: impacto distributivo dos ganhos de produtividade da agricultura brasileira. Instituto de Economia Agrícola. Coleção Estudos Agrícolas 2, 1995. 244p.

SMITH, Adam. A riqueza das nações: investigação sobre sua natureza e suas causas. São Paulo, Abril Cultural, (Série os Economistas), vol. 2, 1983. 654p.

SMORINGO, J. N. e SAWAYA, M. J. Análise da eficiência dos sistemas de distribuição de flores e plantas ornamentais no Estado de São Paulo. Revista de Economia e Sociologia Rural. Vol. 39, nº 1. 2000.

SOUZA, F. L. M. Estudo sobre o nível tecnológico da agricultura familiar no Ceará. Fortaleza: UFC/CCA/DEA, 2000. 93p. (Dissertação de Mestrado em Economia Rural).

STÜLP, V. J. Os impactos do mercosul no setor agroindustrial e a pesquisa acadêmica no Brasil. In: Congresso Brasileiro de Economia e Sociologia Rural, 31, Ilhéus, Anais...Brasília: SOBER, 1993. p. 929-941.

VILLWOCK, L. H. M. e GIOCOMINI, N. M. R. Análise comparativa da maçã brasileira no contexto do mercosul. In: Congresso Brasileiro de Economia e Sociologia Rural, 32. Brasília, 1994, Anais ... Brasília, SOBER, 1994. p.485-497. 
REVISTA DE ECONOMIA E AGRONEGÓCIO, VOL.1, No 4 